\title{
ORPHEU, UMA REVISTA-MANIFESTO
}

Jerónimo Pizarro*

Recebido: 05/10/2015

Aprovado: 20/11/2015

Resumo: Nas páginas da Orpheu, a revista que hoje mais identifica o Primeiro Modernismo Português, não apareceu um programa nem um manifesto, embora vários fossem contemplados. Estudar este aparente paradoxo e os planos de publicação desses tipos de textos é o intuito deste artigo. Apresentam-se alguns documentos do espólio pessoano datáveis de 1915-1917.

Palavras-chave: Fernando Pessoa; Orpheu; Modernismo; Manifestos; Planos de Publicação.

\section{ORPHEU, A MANIFESTO-MAGAZINE}

Abstract: In Orpheu's pages, magazine that nowadays is a hallmark of Portuguese Modernism, there has never been a written down program or a manifesto, even though many were considered. This article aims to study such apparent paradox, along the projects related to the texts that were never published. A few documents of Fernando Pessoas's legacy, dated between 1915 and 1917, will be presented.

Key-words: Fernando Pessoa; Orpheu; Modernism; Manifestos; Plans for Publishing.

Celebrou-se, em 2015, o centenário da revista Orphen (1915), que foi o epicentro de um breve terramoto nas letras lusas, mais tarde conhecido como o Primeiro Modernismo Português. Outras revistas agitaram, sem abalar, o meio artístico de Lisboa, quase como réplicas de escassa magnitude, e a única que poderia ter causado um novo abalo, Portugal Futurista (1917), foi apreendida pela polícia pouco depois de sair para as bancas. Lida em retrospectiva, Orpheu parece-nos relativamente convencional - exceptuando, é claro, os textos de Álvaro de Campos e de Mário de Sá-Carneiro (não os de Pessoa, cujo "Marinheiro" depois de doze minutos faz com que "os mais ágeis e astutos" se sintam “com sono e brutos”, PESSOA, 2014, p. 228) - e surpreende-nos que tenha agitado tanto o ambiente literário, como demonstram os recortes de imprensa que foram coleccionados por Pessoa e Sá-Carneiro (cf. PESSOA, 2009, pp. 663-668), atendendo a que: 1) alguns dos textos mais agressivos e provocadores de 1915 não foram publicados em Orphen 1 ou Orphen 2; 2) os temas sensíveis da guerra e da situação política em Portugal estiveram ausentes da revista; 3) nenhum dos dois números publicados veio acompanhado de um programa ou manifesto. Textos como o poema "A Cena do Ódio", publicado parcialmente apenas em 1923, escrito durante os poucos dias que durou a revolução de 14 de Maio de

\footnotetext{
* Professor na Universidad de los Andes / Facultad de Artes y Humanidades.
} 
1915, o panfleto O bando sinistro - Appello aos Intellectuaes Portuguezes (Julho 1915), assinado por "Raul Leal, Collaborador de 'Orpheu", ou o Manifesto Anti-Dantas e por Extenso (Outubro 1915 - Junho 1916), assinado por “José de Almada Negreiros, Poeta d'Orpheu, Futurista e Tudo", são três textos que, tal como o Ultimatum de Álvaro de Campos, não chegaram a integrar as páginas publicadas do Orphen (o poema "A Cena do Ódio" figura apenas nas provas de página de Orpheu 3, de 1917). Temas como a guerra, palavra que, como indicou Steffen Dix (2015, p. 25), surge apenas uma vez nas 247 páginas da revista, ou a revolução de 14 de Maio de 1915, nunca mencionada, apesar de ter sido a mais sangrenta da história portuguesa, como frisou José Barreto (2015, p. 71), são temas que simplesmente estão ausentes. Por outro lado, nem Orphen 1 nem Orpheu 2 contêm um programa ou um manifesto, sendo que a introdução de Luís de Montalvor ao primeiro número é um convite ao exílio, a um exílio mais decadentista, ao estilo de Joris-Karl Huysmans, do que modernista, ao estilo de James Joyce. Então, porque provocou Orphen tamanha agitação?

Neste artigo, não procurarei responder a esta pergunta de carácter mais geral, que talvez nos conduzisse a um estudo do meio intelectual português em 1915 e a revisitar os três vocábulos pejorativos em dias de Orpheu, segundo José de Almada Negreiros ("botas de elástico", "literatura" e "lepidóptero"; cf. NEGREIROS, 2015, pp. 26-30), mas apenas contribuir para a discussão e elucidação do último ponto que foquei: não terá faltado um programa ou um manifesto à revista-insígnia do Primeiro Modernismo Português? Para responder a esta pergunta revisitarei a revista Orpheu, apoiando-me na edição fac-similada editada pela Tinta-da-china (2015), bem como os planos de publicação de 1915-1917, incluídos no volume X da Edição Crítica de Fernando Pessoa, Sensacionismo e Outros Ismos (2009).

Orpheu 1 não continha nada que causasse, por si só, grande inquietação, se exceptuarmos o facto de se apresentar como um empreendimento luso-brasileiro (para quem desconhecesse a literatura transatlântica), o de ter como editor simbólico um menor de idade, António Ferro (embora ninguém tenha reparado), o facto de conter um soneto, "Torre Ignota" de Ronald de Carvalho, sem pontuação (embora tal se deva a uma decisão editorial de Pessoa e Sá-Carneiro para perturbarem os críticos, que, com certeza, não tinham lido Mallarmé; cf. PESSOA, 2009, p. 91), e pouco mais. Talvez também a capa de José Pacheco, com uma mulher nua entre dois altos círios, como se se tratasse de um 
enterro (disseram as más línguas da época); sem dúvida os poemas de Sá-Carneiro, especialmente o poema intitulado "16", que terminava com versos de que se fez troça, “Olha, lá vai êle a valsar / Vestido de casaca, nos salões do Vice-Rei”, ORPHEU, 2015, p. 12); e, manifestamente, a "Ode Triunfal", bem mais do que o "Opiário", de Álvaro de Campos, um opiómano inexcusável. Tal, porém, era pouco, ou pelo menos dizia respeito a poucos, praticamente só a Campos, de quem se tinha um autorretrato irónico: "Eu sou monárquico mas não católico / E gostava de ser as coisas fortes” (ORPHEU, 2015, p. 73). Sem o "r-r-r-r-r-r-r eterno" (ORPHEU, 2015, p. 77) da "Ode Triunfal”, Orpheu 1 poderia, porventura, ter chocado menos. Mas essa ode de Campos encerrava provocatoriamente a revista e faria parte "Dum livro chamado Arco de Triunfo, a publicar" (ORPHEU, 2015, p. 83) ou "em preparação" (ORPHEU, 2015, p. 2). Quem tivesse ficado indisposto com Campos, haveria de ter Campos a dobrar.

Junto com o primeiro número da revista, vinha também uma folha solta, com um anúncio duplo e algo enigmático, que deve ter gerado grande curiosidade (insiro duas metades que se conservam no espólio pessoano):

Vêr no II numero de "ORPHEU", a saír em junho:

Colahoração especial do futurista Santa Rita Pintor 


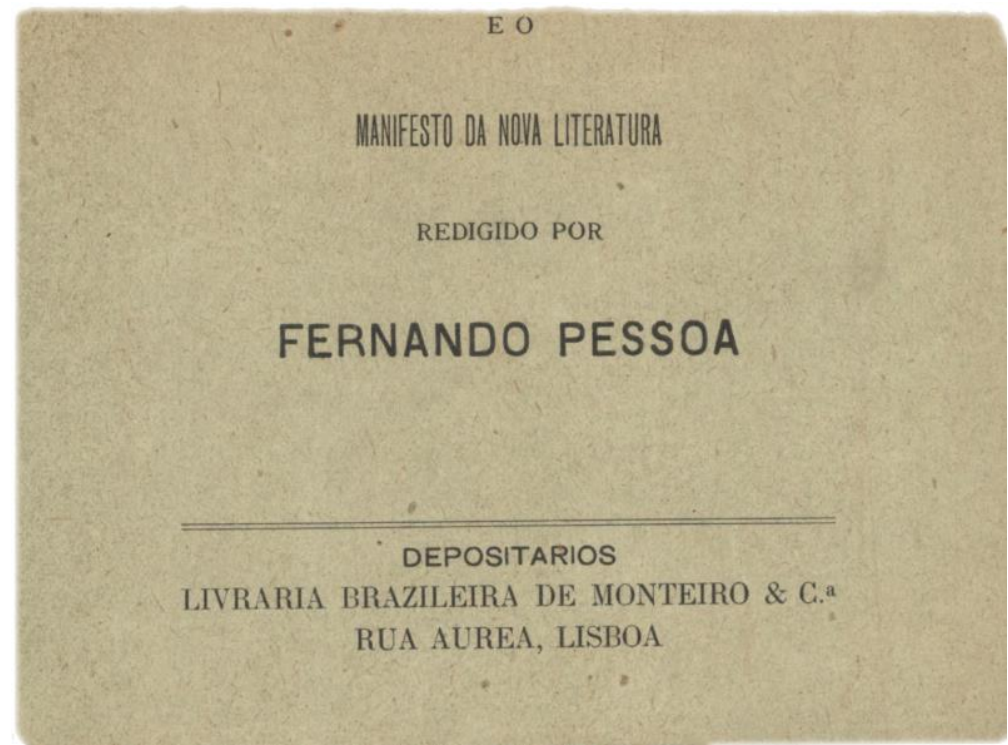

$\left[\mathrm{BNP} / \mathrm{E} 3,48 \mathrm{D}-12^{\mathrm{v}}\right.$ e $\left.49 \mathrm{~A}^{4}-31^{\mathrm{v}}\right]$

No verso desta folha de $18,8 \times 13,8 \mathrm{~cm}$, Pessoa redigiu não o prometido manifesto, mas uma série de outros textos: em 12v, alguns apontamentos (ver PESSOA, 2009, pp. 150 e 522); em $31^{v}$, um soneto inglês datado:
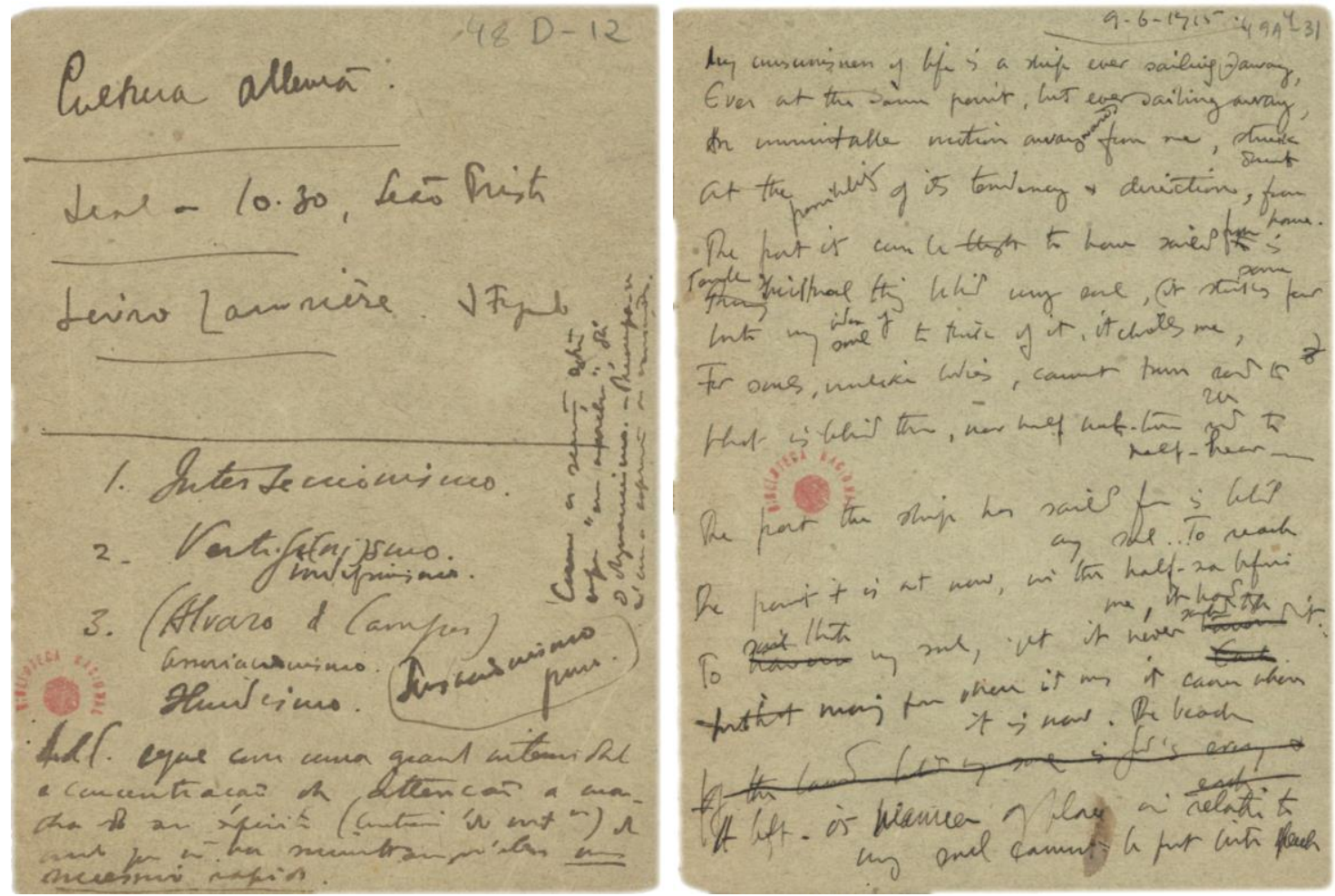

$\left[\mathrm{BNP} / \mathrm{E} 3,48 \mathrm{D}-12^{\mathrm{r}}\right.$ e $\left.49 \mathrm{~A}^{4}-31^{\mathrm{r}}\right]$ 
Tal revela-nos que, em Junho de 1915, Pessoa concebeu uma distinção entre o "Interseccionismo" e o "Vertiginismo" ou "Vertigismo" (com a palavra "indefinismo" por baixo), e que a Álvaro de Campos atribuiu o "Associasionismo" e o "Hinduismo", possíveis formas do "Sensacionismo puro". Daí a observação que se encontra na margem inferior e se prolonga na direita:

"A[lvaro] de C[ampos] segue com uma grande intensidade e concentração de attenção a marcha do seu espirito (contrario do int[erseccionis]mo) de modo que não ha simultaneo n'elle mas successivo rapido. Como as sensações estão sempre 'em marcha', dá o dynamismo. Preoccupa-se n’uma expressao das sensacões”.

A prometida colaboração de Santa Rita Pintor teve de facto lugar, e Orpheu 2, já com novos directores, continha "4 hors-texte duplos" do Pintor, tão criticado por SáCarneiro na sua correspondência com Pessoa e com quem Almada cortaria relações, já cansado de quem se bastasse "com a notoriedade de andar por aí a brilhar em 'histórias do Santa-Ritta" (NEGREIROS, 2015, p. 10). Mas onde estava o "Manifesto da nova literatura"? Onde estava o Arco de Triunfo?

Orpheu 2 custava os mesmos 30 centavos, veio a público com uma capa tipográfica que terá constituído uma grande novidade e era abertamente mais escandalosa. Anunciava uma "longa série de conferências de afirmação" na rentrée; abria com poemas inéditos de um poeta oficialmente alienado, Ângelo de Lima, respondendo assim, com elegância, às acusações de alienação dos seus colaboradores por parte dos psiquiatras portugueses que leram Orpheu 1; continha "Poemas sem Suporte", de Mário de Sá-Carneiro, e nomeadamente uma suposta "blague", "Manucure", poema que entre uma frase caligramática e uma série de gritos, fazia o elogio da industria tipográfica; incluía a colaboração de uma tal "Violante de Cysneiros (?)", com ponto de interrogação, como se alguém não se responsabilizasse pela sua autoria; incluía a "Ode Marítima" de Álvaro de Campos, com todo o seu sadomasoquismo, e poemas interseccionistas de Fernando Pessoa, que parecia passar de um mundo nebuloso, o do paulismo, para um outro, o do interseccionismo. Orpheu 2 já nem precisava, a bem dizer, de um programa ou de um manifesto para cativar a atenção, até porque Pessoa já transitava para o sensacionismo, embora a promessa ainda se mantivesse. Na página 83, lê-se: "O Manifesto da Nova Literatura, que havia sido anunciado como devendo fazer parte do n. ${ }^{\circ} 2$ de ORPHEU, não 
é nêle inserto nem o acompanha”. O motivo? Problemas, por assim dizer, técnicos: "envolvendo a confecção dêsse manifesto o desenvolvimento de principios de ordem altamente scientifica e abstracta, êle não pôde ficar concluido a tempo de ser inserto".

Qual teria sido esse manifesto? Uma possibilidade é que desse texto se tenham conservado rascunhos no espólio pessoano e que um dos vários textos encimados pela indicação "Manifesto" em Sensacionismo e Outros Ismos (2009) possa ser um testemunho do Manifesto da Nova Literatura. Por exemplo, talvez se tratasse do último texto do capítulo III, dedicado ao Interseccionismo, atendendo a que "foi manuscrito numa folha em que já constavam os nomes de Raul Leal e Violante de Cysneiros (Côrtes-Rodrigues), colaboradores do 2. ${ }^{\circ}$ número de Orpheu” (PESSOA, 2009, p. 131):

\begin{abstract}
Manifesto:
Antigamente os homens não tinham perfeita consciencia de si-proprios. Só modernamente é que isso acontece. Só modernamente, portanto, pode haver uma arte verdadeira.

Antigamente existia mais o mundo-exterior que o interior, que, hoje, desde Kant, reconhecemos como o unico real. A arte grega é toda falsa.

Mediante as velocidades e as complicações materiaes creadas pelos productos da sciencia, conseguimos que a Materia nos fizesse compenetrados da vertigem do Espirito, da actividade espiritual.

Pela Machina, pela Sciencia, a Materia espiritualizou-se, porque a Sciencia é a espiritualização da Materia, a imposição, a ella, do Espirito. Porisso só modernamente começa a perfeita conformidade da Materia com o Espirito, a Edade de Urano que vae raiar.

Interseccionismo analytico.
\end{abstract}

(PESSOA, 2009, pp. 130-131)

Não sei se este texto requeria "o desenvolvimento de principios de ordem altamente scientifica e abstracta", mas o certo é que a fusão deste texto com os outros intitulados "Manifesto" teria obrigado Pessoa a preparar um texto único, analiticamente complexo e demorado.

Num texto anterior ao presente, intitulado "Orpheu: não falta um prefáciomanifesto?" (PIZARRO, 2015), remeti para uma hipótese já levantada em Sensacionismo e Outros Ismos (2009): tal como podemos percorrer os textos sobre interseccionismo, em que Pessoa se aproxima de uma literatura "decomposicional", visto que a sucessão paulismointerseccionismo-sensacionismo tem um correspondente nos períodos do cubismo - préanalítico, analítico e sintético -, também podemos percorrer os textos que compõem a génese do Ultimatum de Álvaro de Campos, que começa a ser escrito em 1914 e que, no 
início, carece de atribuição autoral. Neste sentido, convém inserir o fac-símile de uma lista de Manifestos sensacionistas (PESSOA, 2009, p. 334), que nos revela quantos manifestos Pessoa imaginava escrever por volta de 1915, o que aumenta a nossa perplexidade ao não encontrarmos nenhum nas páginas da revista, ou em opúsculo ou folheto.

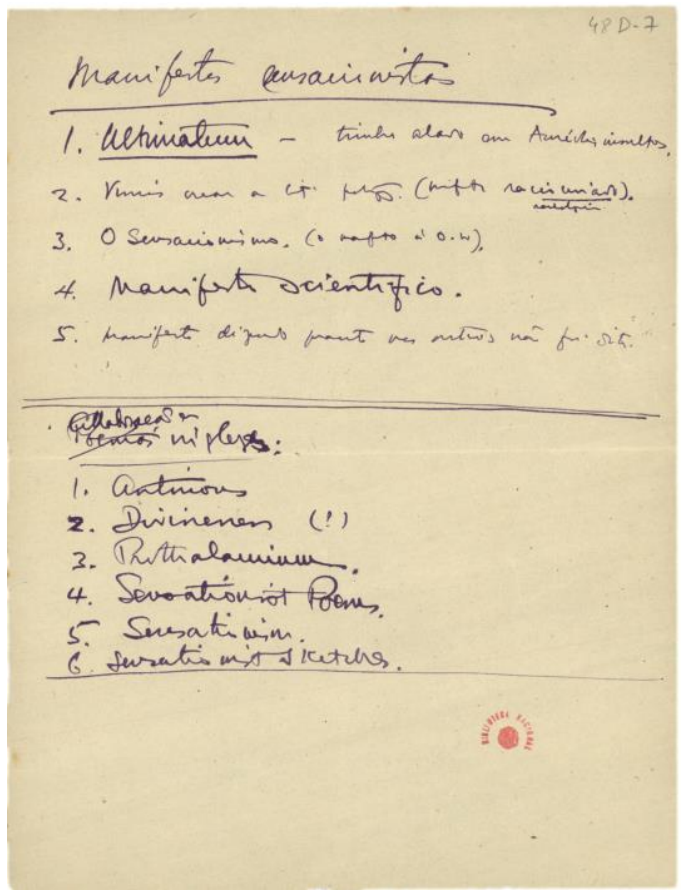

\section{Manifestos sensacionistas}

1. Ultimatum - timbre alado em Auréola: insulto.

2. Vimos crear a lit. portugueza. (manifesto sociologico).

3. O Sensacionismo. (manifesto á $\mathrm{O}[\mathrm{scar}] \mathrm{W}[\mathrm{ilde}]$ ).

4. Manifesto scientifico.

5. Manifesto dizendo quanto nos outros não foi dito.

Collaboração em inglez:

1. Antinous

2. Divineness (?)

3. Prothalamium.

4. Sensationist Poems.

5. Sensationism.

6. Sensationist Sketches.

O primeiro manifesto é o texto que se destinava, originalmente, à revista Europa, anterior a Orpheu, que abriria com um texto escrito "com collaboração ocasional do SáCarneiro", sendo, segundo Pessoa, "uma das principaes affirmações a da nossa necessidade de 'reagir em Leonino' contra o ambiente” (PESSOA, 2009, p. 88). Esse texto seria o seguinte:

1. Dado ser proximo, o definitivo apparecimento do poeta maximo da nossa Raça, e do Mundo Moderno, já anunciado, mesquinhamente é certo, pelo nome ainda pouco aureo e sem nexo sphyngico de superCamões; certa a necessidade de reagir em Leonino contra a Vida, como a entendem os que vivem e trabalham; incurso em resvalamentos para popular o intuito pictural de se fazer entender - convem dar á Revolta dos Superiores a sua Bandeira Errada e ao Elmo Essencial do Brazão outro e remoto o seu Timbre alado em auréola.

2. Os futuristas - embolal-os, Europa estropiada, salchicharia de ansias, fogos-fátuos ás avessas, ruinas do Moderno... 
Os cubistas - escada abaixo! cosinheiros de geometria, ex-choques-decomboios recuando ferrugentos, caixotes abertos no Caes - para quê tão pouco e tão em emigração da Extranheza?

O Orphismo - descabelal-o. A agua de Apollinaire - deitar fóra a agua e a garrafa depois. Todas as artes e ismos e istas... provinciaes em Paris... cubismos que perderam o chapeu... vinho do Porto fechado em Londres. - Nota para os sequestrados - o vinho do snr. Guilherme Apollinaire. (PESSOA, 2009, p. 115).

A revista Orphen acabou por aparecer sem um manifesto, mas diversos textos, de diversa índole, poderiam ter acompanhado um dos números. Hoje, em retrospectiva, podemos ler alguns desses fragmentos e imaginar o seu enquadramento no espaço da revista ou no tempo dela.

Não é apenas a ausência de um texto mais ou menos programático o que me surpreende. Surpreende-me também a ausência de outros textos de Álvaro de Campos, que, em 1915, é o melhor leitor de José de Almada Negreiros - daí as dedicatórias mútuas de poemas - e que, por vezes, quase parece um heterónimo almadiano. Em 1915, quem escrevia os textos mais violentos, mais desassossegadores, mais politicamente incorrectos, mais "futuristas e tudo", mais sensacionistas eram, sem dúvida, Campos e Almada. Porque não surgiu em Orpheu a "Saudação a Walt Whitman", que tanto deve a "A Cena do Ódio"? Porque permaneceu a "Ode Marcial”, que fala da Grande Guerra, arquivada nas arcas pessoanas? Porque não chegou o Ultimatum a ser órfico? Talvez tenha sido apenas uma questão de falta de tempo e de recursos. É pelo menos essa a impressão que os planos nos deixam.

Passemos a Orphen 3 e vejamos o que poderia ter incluído. Lembremos, antes, que as provas de página de 1917, tardiamente reveladas, tinham mais poemas de Sá-Carneiro, mais poemas de Pessoa (a gramática de "A Voz de Deus" teria gerado incompreensões), "A Cena do Ódio" de Almada, um texto de Coelho Pacheco - que Octavio Paz considerou uma pobre imitação de Campos (PAZ, 1962, p. 21) - e outros textos esquecidos, que dificilmente revoltariam alguém. Nas provas de página não surge Campos, que tinha agitado em 1914-1915 mais do que Pessoa. O poeta escreve:

Lembro-me do Almada Negreiros, depois de ler com enthusiasmo a 'Ode Triumphal', me saccudir fortemente pelo braço, vista a minha falta de enthusiasmo, e de me dizer quasi indignado: 'Isto não sera como v. escreve, mas o que é é a vida'. Senti que só a sua amisade me poupava à affirmação implicita de que Alvaro de Campos valia muito mais do que eu (PESSOA, 2009, p. 89). 
E Sá-Carneiro numa carta a Pessoa: "Álvaro de Campos, meu caro amigo, não é maior com certeza que Fernando Pessoa, mas consegue ser mais interessante do que ele" (carta de 24-XII-1915, em coleção particular). Porém, Campos tinha sido contemplado em diversos momentos.

Em carta de 31 de Agosto de 1915, Sá-Carneiro responde a Pessoa: "Concordo intensamente com tudo quanto você diz do Orfeu 3. Claro que é imprescindível o nosso Engenheiro - e vincadamente pelas razões que aponta: Capital etc.” (cota 1156-69). No plano inserido nessa carta, surge outro dos poemas do livro Arco de Triunfo: "A Passagem das horas". De certa forma, todos os textos do livro foram contemplados, mas o livro nunca foi concluído, porque depois da "Ode Triunfal" e da "Ode Marítima", Pessoa nunca terminou as outras peças centrais: "Saudação a Walt Whitman", "Ode Marcial" e "A Passagem das Horas" (cf. PESSOA, 2014, pp. 374-376). Ora, num plano de 1916, em que surge Camilo Pessanha, que seria publicado pela Centauro, Campos e Almada continuam a figurar (PESSOA, 2009, pp. 79-80), tal como numa lista de "Manifestos de Orpheu", de 1917 (PESSOA, 2009, p. 74), ou numa separata de Portugal Futurista (disponível em

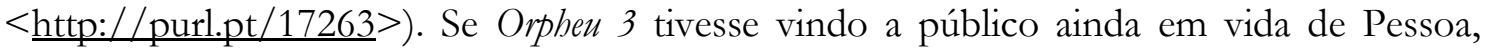
talvez dois poemas afins tivessem surgido juntos: a "Cena" e a "Saudação".
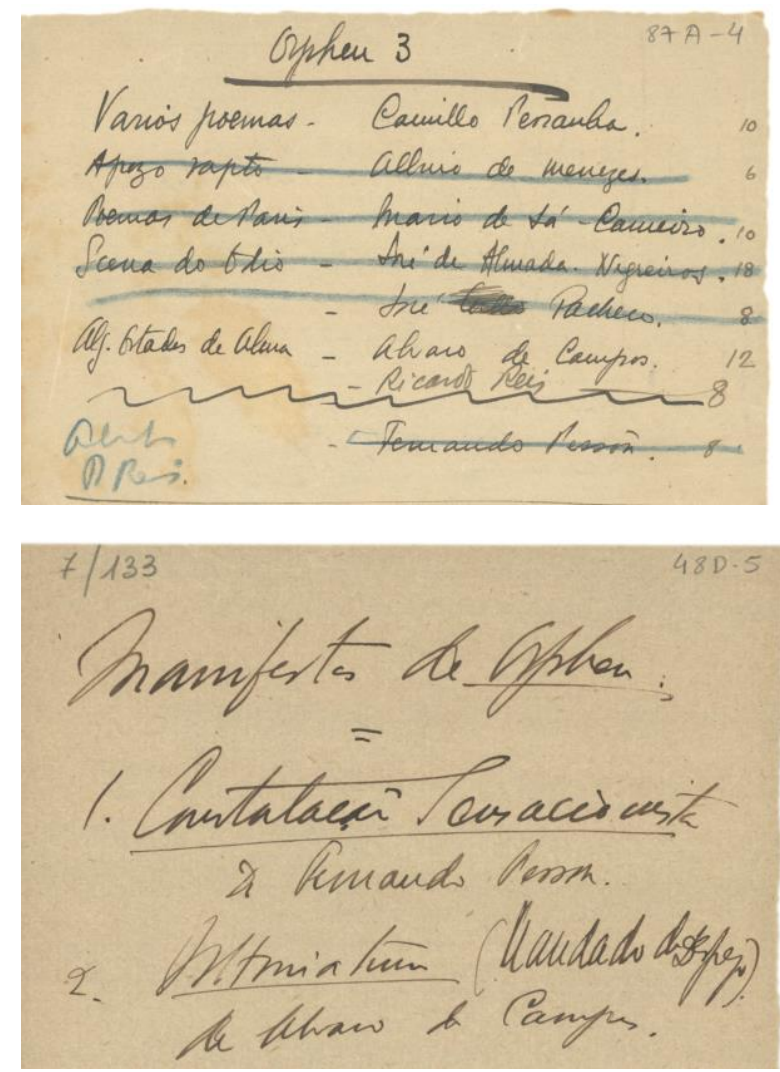

\section{Orpheu 3}

Varios poemas - Camillo Pessanha. $\quad 10$ Apoz o rapto - Albino de Menezes. 6 Poemas de Paris - Mario de Sá-Carneiro. 10 Scena do Odio - José de Almada-Negreiros. 5 口 - José Pacheco. 8 Alg. Estados de Alma Alvaro de Campos. 12 — Ricardo Reis. 8 — Fernando Pessôa. 8

Manifestos de Orpheu.

$$
=
$$

1. Constatação Sensacionista de Fernando Pessoa.

2. Ultimatum (Mandado de Despejo) de Alvaro de Campos. 


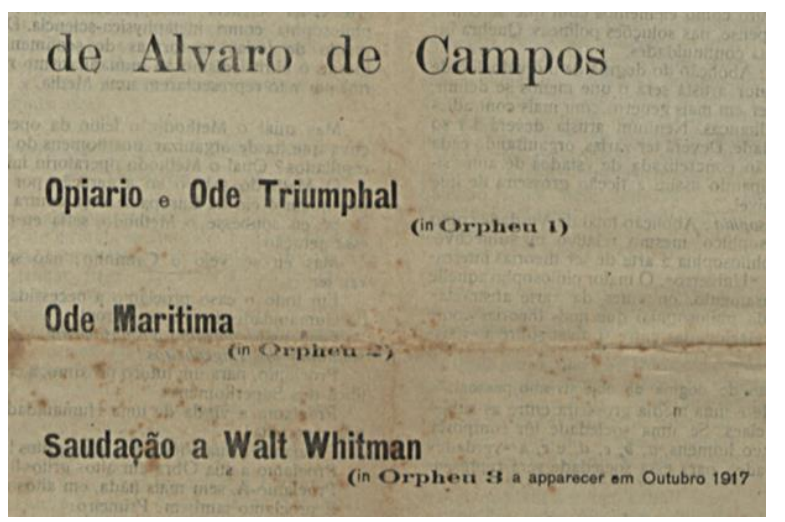

de Alvaro de Campos

Opiario e Ode Triumphal (in Orpheu 1)

Ode Maritima (in Orpheu 2)

Saudação a Walt Whitman (in Orpheu 3

a aparecer em Outubro 1917

Orpheu poderia, enquanto publicação, ter contido textos ainda mais escandalosos e ter sido ainda mais criticada. Não o foi, em parte, porque o número 3 não saiu e porque o Ultimatum e as suas separatas quase nem chegaram a circular. Bastaram, porém, dois números, sem programa nem manifesto nem textos mais violentos do que os de Campos ou mais desconcertantes do que os de Sá-Carneiro, para que uns revoltados anónimos fizessem circular um Orpheu apócrifo e para que Pessoa tenha programado não apenas a defesa da revista, mas também a sua crítica, com o fim de aumentar a visibilidade da mesma (havia já constatado, com entusiasmo, "Somos o assunto do dia em Lisboa", PESSOA, 2009, p. 374).
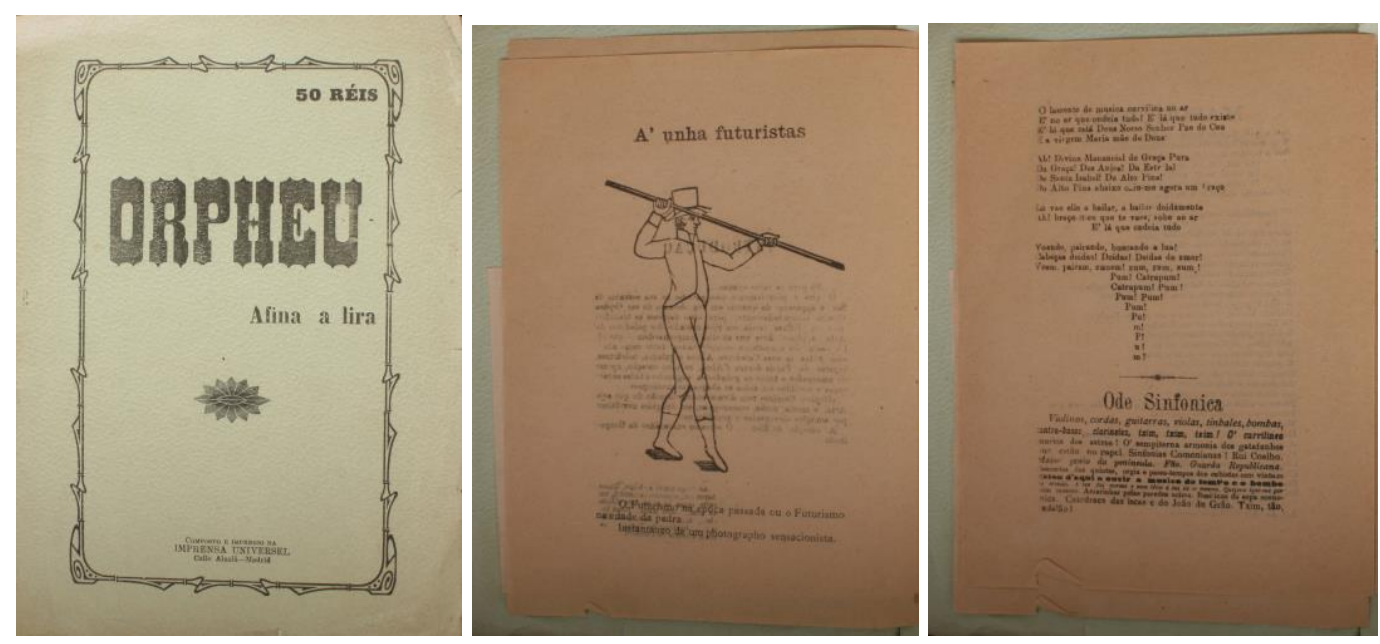

(Disponível em: < http://casafernandopessoa.cm-lisboa.pt/bdigital/8-638MN>).

O local de impressão indicado no interior é Madrid e a tipografia chama-se Imprimerie Universel, o que permite supor que terá sido impresso em Lisboa, por quem não sabia francês e queria criar uma ficção espanhola. É este o folheto ao qual Sá-Carneiro faz 
referência numa carta de 23 de Agosto 1915: "Pelas coisas q[ue] me diz terem saído vejo que se falou bastante do Orfeu - m[ui]to simptomático do sucesso a venda publica - logo: como 'negocio' - dum panfleto sobre o caso. Embora sem interesse gostava de o ver. Decerto você o arquivou no entretanto”. Nessa mesma carta, Sá-Carneiro acrescenta: "Peço-lhe m[ui] to que não descure o rebuscamento dos jornais" (cota $115^{6}-59^{\text {") }}$.

O Orphen apócrifo tem, efectivamente, escasso interesse - e pode hoje ser consultado no site da Biblioteca Digital de Fernando Pessoa. Bem mais interessante, porém, é o facto de Pessoa ter projectado um folheto contra Orphen, talvez em Julho ou Agosto de 1915. Nesse folheto, também publicado em Sensacionismo e Outros Ismos (PESSOA, 2009, pp. 62-64), Pessoa oferece-nos a "melhor" crítica à revista, quase intimando a que o nível da crítica contra a revista fosse mais elevado; quase requerendo que existissem contendas, mas que estas tivessem alguma profundidade e conteúdo. Citando "Manucure", um poema que talvez tenha ajudado a compor tipograficamente, diz Pessoa: "no Manucure o sr. Sá-C[arneiro] inseriu annuncios de coisas futeis. Ora sem duvida que seria genial cantar o annuncio, mas o interessante era fazel-o sem inserir esses annuncios em typo quase de cartaz!”. De si próprio, escreve: “O Marinheiro do sr. F[ernando] $\mathrm{P}$ [essoa] é de partir a cabeça mais solida. Ninguem percebe nada, salvo, aqui e alli, umas frases que era melhor não perceber. Em todo o caso, o sr. tem a grande vantagem de não cometer immoralidades nem espalhafatos”. Sobre os colaboradores brasileiros, tem duas frases lapidares: "O sr. R[onald] de C[arvalho] é um exemplo de symbolista, assim como o sr. Ed[uardo] Guimarãens. O crime de ambos é muito menor". E sobre um verso da "Ode Triunfal", altamente escandaloso, "Ó automoveis apinhados de pândegos", interroga-se como um moralista: "Qual é a necessidade d'esta ultima palavra? Nenhuma. É porque é obscena que o autor a emprega”. Pessoa não foi apenas o seu melhor crítico num sentido positivo - no sentido em que Eduardo Lourenço o entende -, mas também o seu melhor crítico num sentido negativo, quando, para gerar discussão, tentava ser o diabo, o advogado do diabo e o acusador do diabo.

Encetei este artigo observando que a revista Orphen (1915) foi o epicentro de um breve terramoto nas letras lusas, e tenho vindo a sugerir que esse desastre artístico poderia ter tido uma amplitude bastante maior. O investigador Steffen Dix costuma citar uma passagem do diário de Aleister Crowley, "God once tried to wake up Lisbon - with an earthquake; he gave it up as a bad job" (in PASI, 2012, p. 264), concluindo, como bom 
alemão: Nem com um terramoto Deus conseguiu despertar Lisboa. Pessoa deverá ter sentido que Orpheu não agitara suficientemente o ambiente literário - basta abrir a revista Atlântida, uma publicação "lepidóptera", contemporânea da Orpheu, para o confirmar. Apercebeu-se, porém, que havia contribuído para que algo de marcante sucedesse, visto que, por volta de 1917, imaginou um diálogo entre Fernando Pessoa e Vicente Guedes, em que se referia à revista nos seguintes moldes:

Fallei-lhe da revista Orpheu, que havia pouco apparecera. Elle elogiou-a, elogiou-a bastante, e eu então pasmei deveras. Permitti-me observar-lhe que estranhava, porque a arte dos que escrevem em Orpheu soe ser para poucos. Elle disse-me que talvez fôsse dos poucos (PESSOA, 2013, p. $34)$.

Pessoa continuou, além disso, a fazer horóscopos e cálculos astrológicos que dizem respeito a Orphen muito depois de 1915, legou-nos umas páginas em que narra a história da revista, nunca abandonou o sonho de publicar Orpheu 3 - em 1915, entre 1915-1917, ou ainda em 1935 - e afirmou por diversas vezes que, ainda que Orphen terminasse, Orphen haveria de continuar. Hoje sabemos o lema de cor: Orpheu terminou; Orpheu continua (cf. PESSOA, 1935, p. 3). De facto, Orphen é hoje mais do que Orpheu. É a revista, mas é também uma geração, um movimento, um momento histórico e um conjunto de recordações e homenagens. É ainda a sua frescura e precocidade. Talvez convenha lembrar a surpresa de Octavio Paz quando descobriu Orpheu e, nomeadamente, Fernando Pessoa. Paz não hesitou em afirmar que a poesia moderna tinha surgido mais cedo em Portugal que em Espanha, ou nos países de língua espanhola (PAZ, 1962, p. 28). Como poderiam certas composições ser apreciadas e não gerar desassossego? Orpheu poderia ter tido um programa ou um manifesto, poderia ter contido outros textos veementes, mas poemas como a "Ode Marítima" foram já um autêntico tsunami. Nem dez ultimatos e dez manifestos da nova literatura provocariam um tamanho deslocamento de massas linguísticas. Por isso, na ausência de um texto-proclama, talvez convenha considerar Orpheu, no seu conjunto, uma revista-manifesto. 


\section{Bibliografia}

BARRETO, José. "O ano do Orpheu em Portugal", in 1915 - O Ano do Orpheu, Lisboa: Tinta-da-china, 2015, pp. 67-95.

DIX, Steffen. "O ano de 1915. Um mundo em fragmentos e a normalização dos extremos", in 1915 - O Ano do Orpheu, Lisboa: Tinta-da-china, 2015, pp. 15-34.

NEGREIROS, José de Almada. Orpheu 1915-1965. Paginação de Rita Lynce sobre maquete original e concepção gráfica de José de Almada Negreiros em 1965. Lisboa: Ática, 2015.

ORPHEU. Edição fac-similada da revista. Lisboa: Tinta-da-china, 2015. Tipo de capa: caixa forrada a tecido e serigrafada. Edição exclusiva e numerada, que inclui fac-símiles perfeitos dos números 1 e 2, bem como as provas tipográficas do número 3.

PASI, Marco. "September 1930, Lisbon: Aleister Crowley's lost diary of his Portuguese trip". Pessoa Plural - A Journal of Fernando Pessoa Studies, n. ${ }^{\circ}$ 1, Primavera, 2012, pp. 253-283. Disponível em:

$<$ https://www.brown.edu/Departments/Portuguese_Brazilian_Studies/ejph/pessoaplural /Issue1/PDF/I1A07.pdf>.

PAZ, Octavio. "El desconocido de sí mismo", in Antologia [de Fernando Pessoa], México: UNAM, 1962, pp. 11-40.

PESSOA, Fernando. Livro do Desassossego. Edição de Jerónimo Pizarro. Lisboa: Tinta-dachina, 2013.

“Nós os de 'Orpheu”'. Sudoeste, n. ' 3, Lisboa, Novembro, 1935, p. 3.

- Obra Completa de Álvaro de Campos. Edição de Jerónimo Pizarro e Antonio Cardiello; colaboração de Jorge Uribe e Filipa Freitas. Lisboa: Tinta-da-china, 2014.

. Sensacionismo e Outros Ismos. Edição crítica de Jerónimo Pizarro. Lisboa: Imprensa Nacional-Casa da Moeda, 2009.

PIZARRO, Jerónimo. “Orpheu: não falta um prefácio-manifesto?”. Nova Águia - Revista de Cultura para o Século XXI, n. ${ }^{\circ}$ 15, Sintra, Zéfiro, 2015, pp. 16-18. 